\title{
Numerical Magneto-Mechanical Analysis of Destructive Coils with Reinforcement Cylinders of Various Thicknesses
}

\author{
R. KaČianauskas ${ }^{a, *}$, A. KaČeniauskas ${ }^{a}$, E. StupaK $^{a}$, S. BalevičIUs ${ }^{a, b}$, \\ N. ŽURAUSKIENE $\dot{E}^{a, b}$ AND J. NOVICKIJ ${ }^{a}$ \\ ${ }^{a}$ Vilnius Gediminas Technical University, Saulètekio 11, Vilnius, Lithuania \\ ${ }^{b}$ Semiconductor Physics Institute, A. Goštauto 11, Vilnius, Lithuania
}

\begin{abstract}
The destructive laboratory device, generating half-period sinus-shaped magnetic field pulses of $0.15-2 \mathrm{~ms}$ duration is investigated numerically. The coil was placed into a steel reinforcement cylinder to resist magnetic forces, while influence of thickness of the reinforcement cylinder is considered in detail. The time-dependent non-linear magneto-mechanical model and the finite element software ANSYS are employed. On the basis of the mechanical analysis, reasonable explanation of the destruction nature is provided. The numerically obtained operation threshold value was in good agreement with experimental measurements.
\end{abstract}

PACS numbers: 02.70.Dh, 73.50.Fq, 75.40.Mg, 75.47.Gk

\section{Introduction}

High pulsed magnetic fields with amplitudes exceeding several tens of $\mathrm{T}$ are very important for the investigation of various material properties and for medical and industrial applications [1-3]. Control and measurement of the parameters of these pulses is a complicated process, since the irregular waveforms of these pulses can contain abrupt rise and decay stages. In order to generate such pulses, it is necessary to induce fast discharge of electric energy cumulated inside the coil. This can be realized via a destructive coil in the following way. An increase in the current flowing through the coil induces a simultaneous increase in the magnetic field and, consequently, mechanical stress. At the particular current thresholds, the mechanical forces may induce critical displacements of the coil windings in the radial direction. As a result, the windings are mechanically damaged and short-circuited.

The present work addresses numerical magneto-mechanical analysis of laboratory equipped destructive coils with reinforced cylinders. Influence of cylinder thickness leading to different destructive mechanisms is considered in detail.

\section{Description of the destructive coil system}

The destructive laboratory device [4], generating half-period sinus-shaped magnetic field pulses of $0.15-2 \mathrm{~ms}$ duration was investigated numerically. It presents the coil mounted inside the steel container to insure safety during experiments. The coil was placed in a steel cylinder to reinforce the construction. The thickness of the varying cylinder wall is defined by $h$. The coil windings

* corresponding author; e-mail: rkac@fm.vgtu.lt were separated from the inner surface of the cylinder by epoxy-glass fiber composite layer.

Due to its axial symmetry, the axi-symmetric formulation of the magneto-mechanical problem is investigated numerically. Finally, the unbounded 2D solution domain defined in the $O x y$ plane is restricted by a rectangular box, where only a quarter of the coil section is considered. The geometry of a quarter section of the device is depicted in Fig. 1.

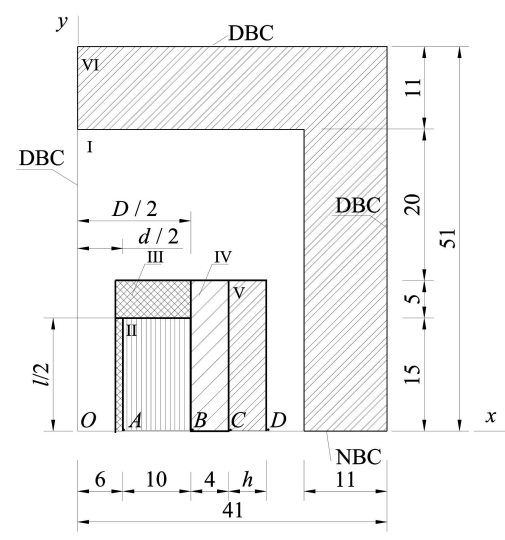

Fig. 1. The geometry of solution domain and boundary conditions.

It consists of six different regions: air (region I), windings of the coil (region II), epoxy-textolite (region III), epoxy-glass separation layer (region IV), reinforcement cylinder (region V), and steel container (region VI). The natural Neumann boundary conditions (NBC) and Dirichlet boundary conditions (DBC) for the magnetic potential are specified. The components of the normal displacements are fixed for the symmetry axis in the mechanical analysis. 
The magnetic properties of these regions are predefined by using the relative magnetic permeability $\mu=1$ for all materials with the exception of the steel, the non-linear magnetic properties of which are defined by the material property curve. The considered materials properties are described in [4].

\section{Results and discussions}

A coupled non-linear magneto-mechanical analysis is employed for numerical investigation of destructive coils. The temporal and spatial evolution of the magnetic flux density $B$ is described by the Maxwell equations [5]. The resulting Lorentz forces are computed from the magnetic flux density. Mechanical behavior of the coil is governed by a time-dependent non-linear equilibrium equation written in terms of time dependent displacements. The finite element method software ANSYS [6] is applied. Details of numerical technique may be found in [7].

The focus of current investigation is influence of the thickness of reinforcement cylinder $h$. Five values of $h=$ 4, 5, 6, 7 and $9 \mathrm{~mm}$ was examined. This influence may be illustrated in terms of the time histories of the von Mises stress $\sigma$ of the outer surface of the reinforcement cylinder (Fig. 2)

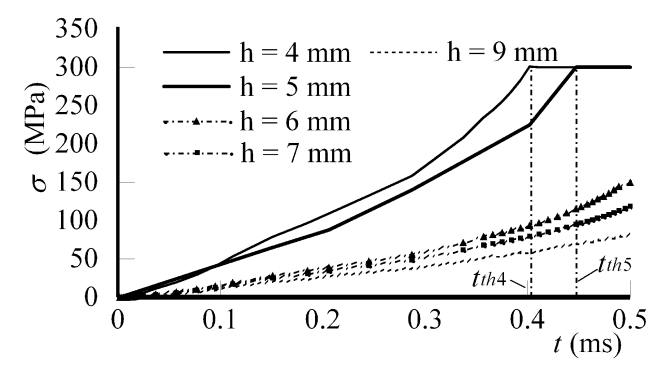

Fig. 2. Time histories of the von Mises stress of the outer surface of the reinforcement.

The graph shows, as one might expect, that only two thinner reinforcements of $h=4 \mathrm{~mm}$ and $h=5 \mathrm{~mm}$ cannot withstand through thickness spreading of plastic deformation. The instant in time at which the coil loses its functionality and the discharge process is termed the "coil operation threshold". In this case, operation threshold is related to opening of plastic hinge. As a result, two different threshold values of time $t_{\mathrm{th} 4 \text { num }}=0.40 \mathrm{~ms}$ and $t_{\text {th } 5 \text { num }}=0.45 \mathrm{~ms}$, are extracted. In contrast, the threshold is not detectable for coils with the thicker reinforcement.

The quality of the numerical analysis for the apparently optimal reinforcement thickness $h=5 \mathrm{~mm}$ is examined by conducting experiments. A comparison of the time histories of the numerically simulated and experimentally measured curves of the magnetic field flux density in the center of the coil is presented in Fig. 3. The experimentally measured curve has two parts. The ascending part indicates the operating coil able to withstand pulsed magnetic loading, while the descending part indicates the abrupt decay of magnetic pulse occurring during coil destruction. The graph shows that the experimental coil operation threshold $B_{\text {th5 }} \exp =37 \mathrm{~T}$, indicating the highest point, was reached at time $t_{\mathrm{th} 5 \text { exp }}=$ $0.45 \mathrm{~ms}$.

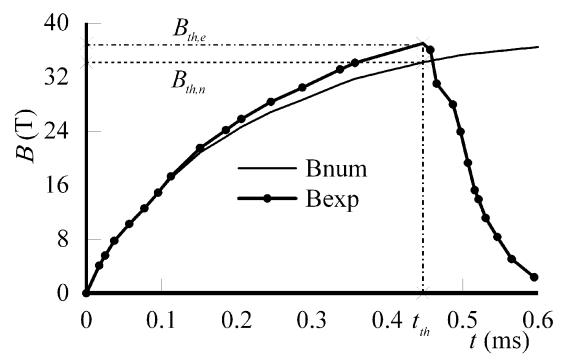

Fig. 3. Illustration of the magnetic threshold and comparison of numerical and experimental results.

A comparison of the results shows perfect coincidence of the numerically and experimentally obtained threshold $t_{\mathrm{th}}$. The indicated $5.4 \%$ difference of the magnetic flux densities between the two curves is within the limits of acceptable tolerance.

\section{Conclusions}

Quantitative results of mechanical analysis provided a reasonable explanation of different destruction nature of the coil. Coils equipped with thicker cylinder reinforcement are characterized by significant deformation of the inside winding layers located close to the coil bore, which leads to local short-circuiting of the windings. On the contrary, coils with relatively thin cylindrical reinforcement are characterized by significant deformation of the entire winding region causing the damage of all windings and abrupt pulse decay. On the basis of the mechanical analysis it was shown that the most suitable thickness of the reinforcement cylinder used for generation of abrupt decay of magnetic field pulses was $h=5 \mathrm{~mm}$. The numerically obtained operation threshold value was in good agreement with experimental measurements.

\section{References}

[1] F. Herlach, Physica B 319, 321 (2002).

[2] H. Witte, H. Jones, Physica B 346-347, 663 (2004).

[3] J. Novickij, V. Stankevič, S. Balevičius, N. Žurauskienè, P. Cimmperman, R. Kačianauskas, E. Stupak, A. Kačeniauskas, M.J. Löffler, Solid State Phenom. 113, 459 (2006).

[4] R. Kačianauskas, A. Kačeniauskas, E. Stupak, S. Balevičius, N. Žurauskienè, J. Novickij, J. Vibroeng. 10, 165 (2008).

[5] O. Bíró, K. Preis, IEEE Trans. Magn. 25, 3145 (1989).

[6] ANSYS Theory Reference, 8th ed., SAS IP Inc., 2003.

[7] S. Balevičius, N. Žurauskienè, J. Novickij, A. Kačeniauskas, R. Kačianauskas, E. Stupak, J. Inf. Technol. Control 3, 54 (2003). 